\title{
REM sleep deprivation increases dominance behaviors in female spiny mice
}

\author{
JOHN D. MOORE and LYN McRAINEY \\ George Peabody College of Vanderbilt University, Nashville, Tennessee 37203
}

and

ROBERT A. HICKS

San Jose State University, San Jose, California 95192

\begin{abstract}
Sixty female spiny mice (Acomys cahirinus) were randomly divided into 20 triad groups and within each triad, assigned to either a REM-deprived (one animal) or a control condition (two animals). Then each triad was given a 30-min pretreatment dominance test. The animals were then subjected to a 4-day treatment period. Immediately after treatment and after a 21-day recovery period, each triad was given a $30-\mathrm{min}$ dominance test. Compared with the controls, the REM-deprived animals showed a substantial increase in dominance behaviors immediately after treatment. All of the REM-deprived animals dominated during the immediate posttreatment test. However, all the REM-deprived animals returned to their pretreatment levels of dominance during the 21-day posttreatment test.
\end{abstract}

In what can best be described as very limited literature, it has been demonstrated that REM sleep deprivation (RD) increases aggression. Specifically, using male rats (only), it has been reported that RD increased nonspecific (Morden, Conner, Mitchell, Dement, \& Levine, 1968), intraspecies (Sloan, 1972), and interspecies (Hicks, Moore, Hayes, Phillips, \& Hawkins, 1979) aggression. The rationale for the present study arose from the perceived needs to extend this relationship beyond its current single-sex/single-species status and to provide a somewhat less ambiguous test of the hypothesis that $\mathrm{RD}$ increases intraspecies aggression, as was the case in Sloan's study.

With regard to the latter point, it should be noted that although Sloan (1972) claimed to have found a positive relationship between $\mathrm{RD}$ and level of intraspecies aggressiveness, this is, in view of the methodology he adopted, a highly tenuous conclusion. To explain, there are two serious flaws in his procedures. First, his data were derived from nonblind ratings of aggressiveness over a 26-day treatment period, which invites the speculation that results may be confounded by an experimenter-bias effect. Second, his RD animals were substantially lower in mean weight than the controls during the course of the 26-day treatment period. Therefore, the changes in aggressiveness that Sloan attributed to $\mathrm{RD}$ could have been the result of differential levels of food deprivation and/or stress between his RD and control groups. Thus, the existence of a relationship between $\mathrm{RD}$ and intraspecies aggression remains an unresolved question.

We express our appreciation to Richard H. Porter, who supplied the animals for this study.

\section{METHOD}

\section{Animals}

The animals were 60 adult female spiny mice (Acomys cahirinus) that were 90 days old at the time of the pretreatment dominance test (weight range $=33-72 \mathrm{~g}$ ). The animals, which had all been born and reared in the laboratory colony, were randomly assigned to 1 of 20 triads. Once formed, these triads were used in each of the three dominance tests; within each triad and on a random basis, two animals were designated as controls and were assigned to one of the following control groups: the home cage control condition (HC), the 4-day dry RD apparatus condition (DC), and the largeplatform wet control condition (LP). The remaining animal in each triad received either a 2-day (SP2) or a 4-day (SP4) period of RD. That is, in all, 40 animals served as nondeprived controls and 20 animals were REM deprived.

\section{REM Deprivation}

RD was achieved using a modification of the water-tank procedure. Unlike the usual procedure, all the animals were individually housed in their $27 \times 16 \times 13 \mathrm{~cm}$ home cages throughout the treatment period. The HC animals were maintained in an unchanged environment. A large pedestal was added to the cages of the DC animals during the 4-day treatment period. For the treatment conditions that required it (i.e., for the LP, SP2, and SP4 groups), the floors of the animals' home cages were covered with water $\left(19^{\circ} \mathrm{C}\right)$ to within $1 \mathrm{~cm}$ from the surface of the platform. Thus, during the treatment period, the LP group spent 4 days on a large platform (diameter $=10.5 \mathrm{~cm}$ ), the SP2 group spent 2 days on large platforms and then 2 days on the small platforms (diameter $=5.0 \mathrm{~cm}$ ), and the $S P 4$ group spent 4 days on the small platform. Thus, the DC group served as a control for the introduction to the home cage of the novel platform and the LP group served as a control for exposure to a wet home cage environment. It should be noted that these platform diameters were adopted using procedures detailed elsewhere (Hicks, Pettey, Okuda, \& Thomsen, 1979) for adapting platform diameters to various-sized animals.

\section{Dominance}

Each triad was given three 30-min dominance tests: one just 
prior to treatment, another immediately after the 4-day treatment period, and the last, 21 days after the treatment period. Each test was conducted in a $51 \times 27 \times 32 \mathrm{~cm}$ open-field apparatus. For each test, the three animals were introduced into the open field in a randomly determined sequence. During the 30 min test period, two observers, who were blind to the animal's treatment, recorded the number of approaches, chases, bites, and displacements made by each animal. These behaviors were selected on the basis of Porter's (1976) research on the agonistic behavior of spiny mice. Since the four behaviors observed are highly intercorrelated (Porter, 1976), these were summed for each animal, to provide a single dominance score for that animal for a given test. It should be noted that the open field was steam cleaned after each test, to eliminate possible olfactory cues.

\section{Procedure}

Prior to the start of the experiment, each animal was handled for a 10-min period each day for 3 days. Just prior to the 4-day treatment period, animals were assigned to triads and, within triads, to treatments. Then the animals in a given triad were weighed and given the pretreatment dominance test. After the 4-day treatment period, each animal was towel dried, allowed a 5-min rest period, and given the immediate posttreatment dominance test. At the conclusion of this test, the animals were weighed again and returned to their individual home cages (which were, as was the case prior to the 4-day treatment period, filled with new sugar cane waste), where they remained until the time of the 21-day posttreatment test. [The difference between the pre- and posttreatment weights for our animals was used as a rough check on differential stress that might be associated with the various treatment conditions. An analysis of these data showed that the treatments did not have a significant effect on weight change; $F(4,55)=1.22$.] Throughout the experiment, food (i.e., Purina Mouse Chow) and water were constantly available, and the animals were maintained on a 12-h light-dark cycle, with lights on at $0600 \mathrm{~h}$. Dominance testing was done between $0600 \mathrm{~h}$ and $1000 \mathrm{~h}$. The room in which the animals were housed was maintained at a constant $21^{\circ} \mathrm{C}$

\section{RESULTS AND DISCUSSION}

Preliminary analyses of the data derived from the control groups (i.e., the HC, DC, and LP conditions) showed that these treatments had no differential effect on the posttreatment tests $(\mathrm{F}=.79$ and $\mathrm{F}=.58$ for the immediate posttreatment test and the 21-day posttreatment test, respectively). Thus, to add power to the analyses, the HC, DC, and LP groups were combined into a single control group (C). A similar set of preliminary analyses of the data derived from the SP2 and SP4 animals showed that there were no significant differences in change in dominance between these groups on either the immediate or the 21-day posttreatment tests $(F=.004$ and $F=.002$, respectively). Therefore, the SP2 and SP4 animals were combined to form a single RD group (SP). Thus, subsequent data analyses and discussion are based on these SP and C groups.

The means and standard deviations for the SP and C groups for each dominance test are given in Table 1. The data summarized in Table 1 were analyzed using a 2 (treatment) by 3 (tests) ANOVA with repeated measures in the second factor. The results of analysis showed that the effects of treatments $[F(1,58)=16.79$,
Table 1

Mean Dominance Scores and Standard Deviations for the REM-Deprived and Control Groups for Each Test

\begin{tabular}{|c|c|c|c|c|c|c|}
\hline \multirow{3}{*}{$\begin{array}{l}\text { Treatment } \\
\text { Condition }\end{array}$} & & & \multicolumn{4}{|c|}{ Posttest } \\
\hline & \multicolumn{2}{|c|}{ Pretest } & \multicolumn{2}{|c|}{ Immediate } & \multicolumn{2}{|c|}{21 Days } \\
\hline & Mean & SD & Mean & SD & Mean & SD \\
\hline REM Deprived & 6.6 & 11.7 & 43.0 & 36.4 & 6.4 & 14.7 \\
\hline Control & 6.6 & 8.3 & 2.1 & 2.9 & 6.6 & 12.9 \\
\hline
\end{tabular}

$\mathrm{p}<.001]$, tests $[\mathrm{F}(2,116)=13.68, \mathrm{p}<.001]$, and the Treatments by Tests interaction $[F(2,116)=62.62$, $\mathrm{p}<.001$ ] were all significant. The reason for these results is readily seen in the pattern of treatment by test means given in Table 1. During the immediate posttest, the SP group showed a substantial increase in dominance behaviors, whereas the $\mathrm{C}$ group showed a decline in these behaviors. However, during the 21-day posttest, mean doninance levels returned to pretreatment levels for both groups. While the changes in dominance during the immediate posttest are striking, these means fail to completely convey the extent to which $\mathrm{RD}$ affected these behaviors in these animals. All of the SP animals were most dominant in their triad during the immediate posttreatment test, and all of the SP animals had returned to their pretreatment position in the triad's dominance hierarchy during the 21 -day posttreatment test.

To the degree that the behaviors observed here reflect intraspecies aggressiveness, these data widen the spectrum of the RD-aggression relationship demonstrated in previous studies. That is, these data give support to the hypothesis that RD seems to act to increase all forms of aggression in a manner that is relatively independent of sex and species. There is, however, in our data, a result that is dissimilar from the results obtained for the effects of RD on nonspecific (Morden et al., 1968) and interspecies (Hicks, Moore, Hayes, Phillips, \& Hawkins, 1979) forms of aggression. Specifically, in each of these studies, fairly high levels of aggression were observed in the RD animals after recovery periods similar to the 21-day period employed in this study. Thus, it may be the case that our finding that all the SP animals had returned to pretreatment levels of dominance during the 21-day test suggests that with respect to aggression, the recovery gradient is dependent upon species, sex, form of aggression, or some combination of these variables.

\section{REFERENCES}

Hicks, R. A., Moore, J. D., Hayes, C., Phillips, N., \& HAwkins, J. REM sleep deprivation increases aggressiveness in male rats. Physiology \& Behavior, 1979, 22, 1097-1100. Hicks, R. A., Pettey, B., Okuda, A., \& Thomsen, D. The effects of REM sleep deprivation and age on locomotor activity in rats. Psychological Record, 1979, 29, 355-360. 
Morden, B., Conner, R., Mitchell, G., Dement, W., \& LEVINE, S. Effects of rapid eye movement (REM) sleep deprivation on shock-induced fighting. Physiology \& Behavior, 1968, 3, 425-432.

Porte R, R. H. Sex-differences in the agonistic behavior of spiny-mice (Acomys cahirinus). Zeitschrift fur Tierpsychologie, $1976,40,100-108$.
Sloan, M. A. The effects of deprivation of rapid eye movement (REM) sleep on maze learning and aggression in the albino rat. Journal of Psychiatric Research, 1972, 9, 101-111.

(Received for publication May 1, 1981.) 